\title{
Recovery of Crude Oil by Chemical Flooding Method Using SDS and Gum Arabic Mixtures
}

\author{
AHMED SONY, HAMDAN SUHAIMI and LAILI CHE ROSE* \\ School of Fundamental Science, Universiti Malaysia Terengganu, Kuala Terengganu, \\ 21030 Terengganu, Malaysia. \\ *Corresponding author E-mail: laili@umt.edu.my \\ http://dx.doi.org/10.13005/ojc/350210
}

(Received: January 22, 2019; Accepted: March 15, 2019)

\begin{abstract}
A group of chemicals known as surfactants are widely used in industries. Their presence in any formulation, albeit little, exhibited superior functionality of the end-products. The dual hydrophobic and hydrophilic moiety of the structure have been shown to be responsible for reduction of surface/ interfacial tension and formation of micelles. In this work, a chemical flooding method using sodium dodecyl sulphate, SDS and its mixture with gum arabic, were carried out to study the recovery and efficiency of extracting the residual oil from the oil reservoirs. Two sets of experiments namely SDS and its mixture with gum arabic flooding at concentrations of SDS between 0.1-0.6 percent by weight are conducted. The percentage of gum arabic used is 16 percent by weight. Results shows that the use of SDS-Gum arabic flooding method yielded higher extraction of oil about 4.0 percent compared to SDS flooding. This suggests that the use of SDS and gum Arabic mixture is more efficient in increasing the amount of oil recovery.
\end{abstract}

Keywords: Enhanced Oil Recovery, Chemical Flooding, Gum Arabic, Viscosity, Surface Tension.

\section{INTRODUCTION}

Oil production has dramatically decreased day by day. With the passing of present time, it is matter of time that oil field discovery is not possible, while the demand for oil is increasing day by day, both in the developed and developing countries. This deficit forced the oil industry to enhance the oil recovery, where less accessible through oil recovery methods. One of the methods in enhanced oil recovery, EOR is surfactant flooding method employed to recover part of the residual oil left behind by water flooding. Surfactant flooding has been around for more than four decades and several reviews have been reported with the recent ones on surfactant flooding ${ }^{1}$, foam assisted ${ }^{2}$ and nanotechnology for $E \mathrm{OR}^{3}$. Surfactants are special compounds that combine hydrophobic and hydrophilic molecules that constitute stable configuration in water and crude oil interfaces. The mixture of oil to a surfactant systems to become microemulsions is another interesting area of research ${ }^{4}$. Surfactants reduced the surface tension between water and crude oil, reduce capillary force and facilitates oil mobilization

This is an Open Access article licensed under a Creative Commons license: Attribution 4.0 International (CC- BY). Published by Oriental Scientific Publishing Company @ 2018 
when surfactant injected with water. Therefore, the choice of surfactants becomes crucial due the complexity of the parameters involved in the recovery process such as temperature, salinity, $\mathrm{pH}$, cost effectiveness, interfacial tension and the structure of the surfactants ${ }^{5,6}$. Another method is the polymer flooding method. The polymers help increase the viscosity of the displacing water to drive the displacing oil to the production well ${ }^{7}$. By that the usage of water is greatly reduced and oil recovery is enhanced, hence more cost effective compared to only water flooding method. These surfactant and polymer flooding are termed as chemical flooding ${ }^{8}$.

The use of surfactant in the oil recovery is well documented ${ }^{1-3}$. However, several works reported different result by using surfactant and polymer. Feng et al., ${ }^{9}$ reported that use of optimal surfactant concentration in oil field $22 \%$ additional oil was recovered by using alkali lignin and partially hydrolyte polyacrylamide (HPAM). It was also reported that due lack enough injection wells in the reservoir. The result was not ideal. Abhijith et al., ${ }^{10}$ conducted the same experiment, where the additional oil recovery was $20 \%$ for surfactant flooding and $23 \%$ for surfactant-polymer flooding. While, Teepols as surfactant and polymer (gum Arabic) for EOR shows an additional oil recovery of $19 \%^{11-13}$, where Abidin et al., ${ }^{14}$ investigated $20 \%$ oil recovery. Santanna et al., ${ }^{15}$, applied EOR method which performed the maximum efficiency in oil recovery measuring $21.5 \%$. This result demonstrated the efficiency of microemulsion in oil recovery which is in direct effect of the viscosity whereby oil was more easily recovered due to lower mobility in the porous medium.

In this present work, it is not meant to be an argumentative in nature but to present the findings from a combination of a surfactant and a polymer at various concentration of surfactant in order to study the effect on the oil recovery and efficiency of extracting the residual oil from the oil reservoirs. The surfactant and polymer used are sodium dodecyl sulphate, SDS and gum arabic, respectively. Standard equipment such viscometer, surface tensiometer and sand pack PVC reactor are used to elucidate the physical parameter such as viscosity, surface tension and the amount of extracted oil.

\section{MATERIALS AND METHODS}

\section{Materials}

The chemicals were of analytical grade and used as received. Arabic gum were purchased from local market and the clean dry silica sand (0.2-0.4 $\mathrm{mm}$ ) were collected from Terengganu sea beach.

\section{Preparation surfactant- polymer solution}

Surfactant and polymer solution were prepared with brine by surfactant of $0.1 \%-0.6 \%$ by weight concentration with $16 \%$ gum arabic (Table 1) using a magnetic stirrer properly mixed and allowed to stay $72 \mathrm{~h}$ to hydrate achieved a desired viscosity to allow for Gum Arabic. The magnetic stirrer performed at 600 (rpm) speed. After performing magnetic stirrer, the sample using the vacuum filter pump for removed by non-dissociated particles. The viscosities were measured using the Brookfield DV-I Digital Viscometer Model LVDV-I

\section{Preparation surfactant solution}

Surfactant solution was prepared with brine by surfactant of $0.1 \%-0.6 \%$ by weight concentration using a magnetic stirrer properly mixed and allowed to stay 36 hours. The magnetic stirrer performed at 200 (rpm) speed. After performing magnetic stirrer, the sample using the vacuum filter pump for removed by non-dissociated particles. The surface tension with and without surfactant was measured by using Force Tensiometer Model Sigma701.

Table 1. Composition of solution for viscosity measurement

\begin{tabular}{ll}
\hline $\begin{array}{c}\text { Solution } \\
\text { No }\end{array}$ & Composition \\
\hline 1 & Water \\
2 & $\mathrm{SDS}(0.1 \mathrm{wt} \%)+\mathrm{NaCl}(3 \mathrm{wt} \%)+$ gum Arabic (16 wt \%) \\
3 & $\mathrm{SDS}(0.2 \mathrm{wt} \%)+\mathrm{NaCl}(3 \mathrm{wt} \%)+$ gum arabic (16 wt \%) \\
4 & $\mathrm{SDS}(0.3 \mathrm{wt} \%)+\mathrm{NaCl}(3 \mathrm{wt} \%)+$ gum arabic (16 wt \%) \\
5 & $\mathrm{SDS}(0.4 \mathrm{wt} \%)+\mathrm{NaCl}(3 \mathrm{wt} \%)+$ gum arabic (16 wt \%) \\
6 & $\mathrm{SDS}(0.5 \mathrm{wt} \%)+\mathrm{NaCl}(3 \mathrm{wt} \%)+$ gum arabic (16 wt \%) \\
7 & $\mathrm{SDS}(0.6 \mathrm{wt} \%)+\mathrm{NaCl}(3 \mathrm{wt} \%)+$ gum arabic (16 wt \%) \\
\hline
\end{tabular}

\section{Preparation of sand pack column}

The core-flood reactor (sand pack pvc reactor) was used in all enhance oil recovery tests, which measures $250 \mathrm{~cm}^{3}$ of bulk volume along with $100 \mathrm{~cm}$ in length and $5.08 \mathrm{~cm}$ diameter. The core-flood reactor was cleaned thoroughly with water and sodium chloride to prevent any other impurity 
during flood testing. Then the reactor was compact (rod) bound with water using dry sand particle (0.2-0.4 mm). The amount of water used for making $100 \%$ saturation of sand pack during this core-flood column is the amount of packing represented pore volume (PV). The ratio between this pore volume $\left(90-90.1 \mathrm{~cm}^{3}\right)$ and bulk volume $\left(250 \mathrm{~cm}^{3}\right)$ is the porosity (\%) of the sand pack column. Before leaving any extra injection, the sand pack reactor lasts 1-2 hours before the experimental temperature $(353.15 \mathrm{~K})$

\section{Procedure for EOR experiments}

The experimental setup used for the investigation, which includes a horizontal PVC core- flood reactor, Peristaltic pump and collection flask. Peristaltic pump (Model: Watson Marlow 120S, Display Type: Digital, Maximum Pressure: $30 \mathrm{psi}$, Motor Type: Brushless DC) was used in the injection of fluids, such as water, crude oil, SDS solution, and polymer solution. Peristaltic pump was used to control the flow rate of flood during the flow rate where all the flood tests were placed at $3 \mathrm{~m} / \mathrm{min}$ ( $3 \mathrm{~cm} /$ minute). Once the sand pack was ready, the column was pre-flushed using the tap water to ensure uniform water involvement, in which the absolute accessibility of the injection fluid (water) was done. During each flood test, the pressure drops (pressure difference between the inlet and outlet) is observed using injection fluid peristaltic pumps for each sequentially. Then, crude oil injection starts in the sand pack column and to ensure complete involvement, the production side (collection flask) continues until the produced water is supplied. During this process, the amount of water produced in the collection flask is considered as the in the original place (OOIP), i.e. the amount of water equivalent to oil saturation. For all EOR tests, initial water saturation and initial oil saturation are calculated using OOIP and PV as shown in the following Equation. (1a) and (1b),

$$
\begin{aligned}
& \text { Swi }=\left(\frac{\text { OOIP }}{\text { PV }}\right) \times 100 \\
& \text { Soi }=\left(\frac{(\mathrm{PV}-\text { OOIP })}{\mathrm{PV}}\right) \times 100
\end{aligned}
$$

Procedure for EOR studies for SDS and SDSGum arabic flooding

Preceding to tertiary (chemical) oil recovery, the oil saturated sand pack was subjected to oil recovery of water injection was initiated in the oil saturated sand pack to mimic the secondary oil recovery operation and was continued until there was no further oil production. The residual oil, which was trapped in the sand pack was called as the remaining oil and is the target for tertiary oil recovery (enhanced oil recovery) process using different type of chemical agents, such as only SDS solution $(3 \mathrm{wt} \% \mathrm{NaCl}+$ $0.1 \mathrm{wt} \%$ to $0.6 \mathrm{wt} \%$ of SDS), SDS + polymer solution (3 $w t \% \mathrm{NaCl}+0.1 w t \%$ to $0.6 \mathrm{wt} \% \mathrm{SDS}+16 \mathrm{wt} \%$ of polymer). At the end of each experiment, water flooding was performed to ensure the removal of the chemicals from the sand pack column shown in Figure 1.

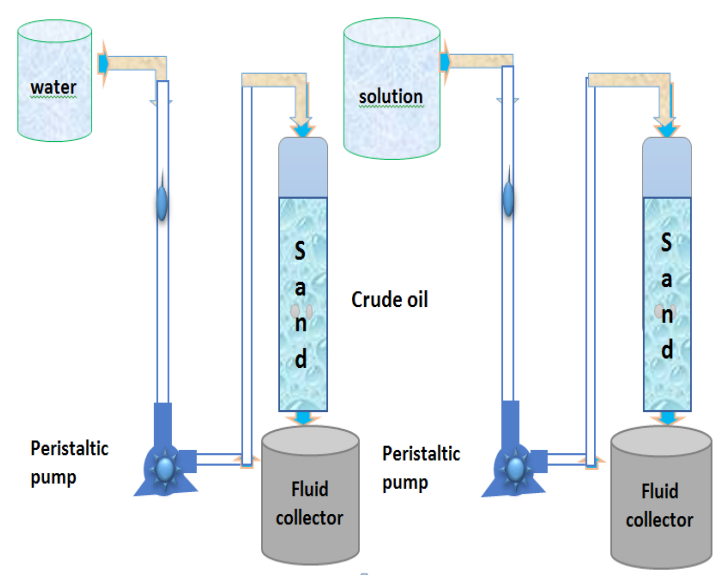

Fig. 1. Schematic representation of the experimental set-up used for the flooding experiment

\section{RESULTS AND DISCUSSION}

\section{Effect of SDS on viscosity}

Viscosity has the most significant impact on water flooding. If viscosity is high, the process efficiency of water displacing oil is high. If viscosity is low, the efficiency of water displacing oil would be low. In order to illustrate the effect of SDS on the viscosity various solution at varied concentration of SDS were prepared and different \% of SDS (Table 1) and plotted as shown in Fig. 2. The result shows that an increment of viscosity with the concentration of solution. This reflect that the viscosity is dependent with the amount of SDS in the solution with a volume $13.1 \mathrm{cP}$ at $0.6 \%$ of SDS.

The increased in viscosity as explained by Hongyan et al., ${ }^{16}$, increase the sweep efficiency of the system.

\section{Effect of SDS on surface tension}

Figure 3 shows the effect of various 
surfactant concentrations in surface tension on oil-brine system. The temperature was set at $90^{\circ} \mathrm{C}$ with ambient pressure. It indicates that $0.1 \%-0.6 \%$ by weight which is equivalent to $0.003-0.02 \mathrm{~mol} / \mathrm{L}$ of SDS were used to measure the surface tension. The result showed that the increment \%weight of SDS reduced the surface tension until at constant with maintaining the $\mathrm{CMC}$ value. This indicates the CMC value of SDS is 0.008 $\mathrm{mol} / \mathrm{L}$ and it is in accordance with $\mathrm{CMC}$ reported in the literature ${ }^{17}$. The ideal range of the percent of surfactant is also on agreement with previously reported to be between $0.1-0.5 \%$ by weight ${ }^{18}$.

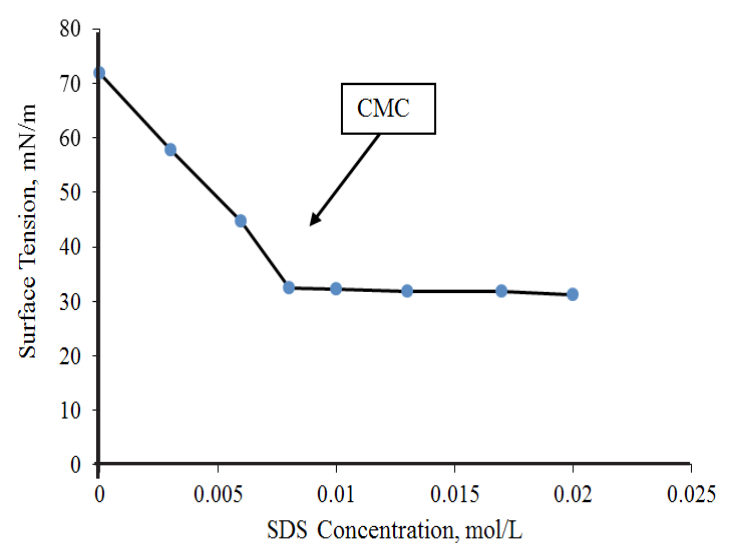

Fig. 2. Viscosity for the water -polymer/surfactant system

\section{SDS and SDS-Gum arabic flooding for additional oil recovery}

Two series of flooding experiments have been conducted to investigate the enhancement

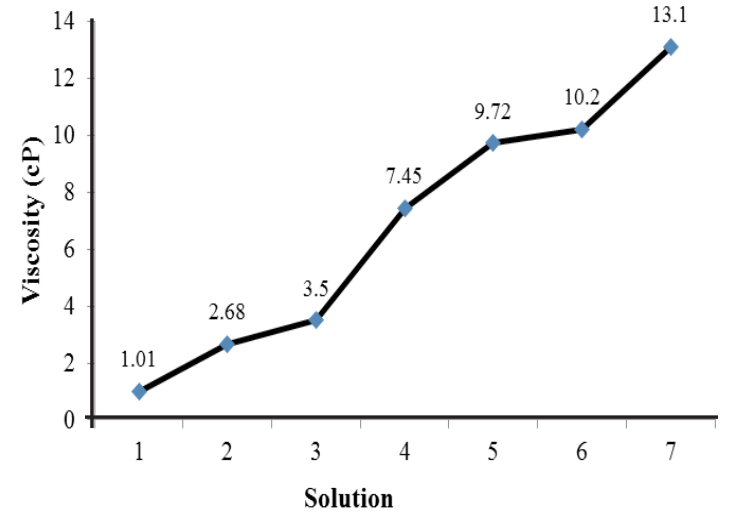

Fig. 3. The variation of surface tension with the concentration of SDS

of oil recovery by using SDS, $\mathrm{NaCl}$ and polymer (gum Arabic). In order to compare the enhancement of oil recovery, firstly flooding experiment was conducted by using water for oil recovery. The respectives values of Swi and Soi for both flooding systems are calculated and tabulated (Table 2 and 3 , for SDS-Gum Arabic and SDS flooding respectively). The amount of oil recovery by water flooding were found to be minimum $59.0 \%$ and maximum $61.8 \%$. Then the SDS-gum Arabic is performed to recover the remaining oil and it is observed that additional oil is recovered with a minimum of $13.0 \%$ and maximum of $25.0 \%$ (Table 2). Similar experiment is repeated but for SDS flooding (Table 3). The results show that after the water flooding, the remaining oil recovered with a minimum of $15.0 \%$ and a maximum recovery of $21.0 \%$ (Table 3 ).

Table 2: The values calculated for SDS-Gum arabic flooding system

\begin{tabular}{|c|c|c|c|c|c|c|}
\hline $\begin{array}{c}\text { Expt } \\
\text { No }\end{array}$ & SP Slug Design & $\begin{array}{l}\text { Oil recovery } \\
\text { by water } \\
\text { flooding }(\%)\end{array}$ & $\begin{array}{l}\text { Additional oil } \\
\text { recovery by SP } \\
\text { flooding(\%) }\end{array}$ & $\mathrm{S}_{\mathrm{wi}}$ & $\begin{array}{c}\text { turation } \\
\mathrm{S}_{\mathrm{oi}}\end{array}$ & $\mathrm{S}_{\text {or }}$ \\
\hline 1 & $\begin{array}{c}\operatorname{SDS}(0.1 \text { wt \%) } \\
+\mathrm{NaCl}(3 \mathrm{wt} \%) \\
+(16 \text { wt \%) gum Arabic }\end{array}$ & 59.0 & 13.0 & 12.8 & 87.1 & 24.7 \\
\hline 2 & $\begin{array}{c}\operatorname{SDS}(0.2 \text { wt \%) } \\
+\mathrm{NaCl}(3 \mathrm{wt} \%) \\
+(16 \text { wt \%) gum Arabic }\end{array}$ & 59.0 & 14.9 & 15.6 & 84.3 & 22.1 \\
\hline 3 & $\begin{array}{c}\operatorname{SDS}(0.3 \text { wt \%) } \\
+\mathrm{NaCl}(3 \mathrm{wt} \%) \\
+(16 \text { wt \%) gum Arabic }\end{array}$ & 61.4 & 16.4 & 13.9 & 86.0 & 21.0 \\
\hline 4 & $\begin{array}{c}\operatorname{SDS}(0.4 \text { wt \%) } \\
+\mathrm{NaCl}(3 \mathrm{wt} \%) \\
+(16 \text { wt \%) gum Arabic }\end{array}$ & 60.8 & 20.0 & 14.4 & 85.5 & 21.0 \\
\hline 5 & $\begin{array}{c}\text { SDS }(0.5 \text { wt \%) } \\
+\mathrm{NaCl}(3 \mathrm{wt} \%) \\
+(16 \text { wt } \%) \text { gum Arabic }\end{array}$ & 61.8 & 25.0 & 15.2 & 84.7 & 20.7 \\
\hline 6 & $\begin{array}{c}\text { SDS }(0.6 \text { wt \%) } \\
+\mathrm{NaCl}(3 \mathrm{wt} \%) \\
+(16 \text { wt } \%) \text { gum Arabic }\end{array}$ & 61.0 & 24.3 & 15.5 & 84.4 & 19.7 \\
\hline
\end{tabular}


Table 3. The values calculated for SDS flooding system

\begin{tabular}{|c|c|c|c|c|c|c|}
\hline $\begin{array}{l}\text { Expt } \\
\text { No }\end{array}$ & $\begin{array}{l}\text { Surfactant } \\
\text { Slug Desing }\end{array}$ & $\begin{array}{l}\text { Oil recovery } \\
\text { by water } \\
\text { flooding(\%) }\end{array}$ & $\begin{array}{l}\text { Additional oil } \\
\text { recovery by SP } \\
\text { flooding(\%) }\end{array}$ & $S_{w i}$ & $\begin{array}{l}\text { uration } \\
\mathrm{S}_{\mathrm{oi}}\end{array}$ & $S_{\text {or }}$ \\
\hline $1 s$ & $\mathrm{SDS}(0.1$ wt $\%)+\mathrm{NaCl}(3 \mathrm{wt} \%)$ & 59.0 & 15.0 & 17.9 & 82.0 & 20.7 \\
\hline $2 s$ & $\mathrm{SDS}(0.2$ wt $\%)+\mathrm{NaCl}(3 \mathrm{wt} \%)$ & 58.9 & 16.1 & 18.8 & 81.1 & 19.1 \\
\hline $3 s$ & SDS $(0.3$ wt $\%)+\mathrm{NaCl}(3$ wt \%) & 59.2 & 17.0 & 18.9 & 81.0 & 19.0 \\
\hline $4 \mathrm{~s}$ & $\mathrm{SDS}(0.4$ wt \%) $+\mathrm{NaCl}(3 \mathrm{wt} \%)$ & 58.7 & 19.4 & 19.0 & 81.0 & 18.9 \\
\hline $5 s$ & SDS $(0.5$ wt \%) $+\mathrm{NaCl}(3 \mathrm{wt} \%)$ & 58.8 & 20.8 & 19.0 & 80.3 & 18.8 \\
\hline $6 s$ & SDS $(0.6$ wt \%) $+\mathrm{NaCl}(3$ wt \%) & 60.0 & 21.0 & 20.0 & 79.9 & 16.6 \\
\hline
\end{tabular}

Effect of SDS concentration on SDS and SDSGum arabic flooding

Figure 4 is plotted in order to facilitate understanding on the effect of SDS concentration on both SDS and SDS-Gum Arabic flooding, The result shows that incremental SDS concentration increases the additional oil recovery with minimum value of $13.0 \%$ at the $0.1 \%$ SDS concentration and a maximum of $25.0 \%$ at $0.5 \%$ surfactant concentration for the SDS-Gum arabic flooding (solid circles of Fig. 4). It is also observed that the highest \% of additional oil recovery was found at $0.5 \%$ concentration of SDS. This result shows that OOIP is increased by increasing surfactants in the surfactant-polymer slug. The excessive recovery of excess oil is achieved at $0.5 \%$ of the recovery and can be attributed to the formation of micelles at $\mathrm{CMC}$ as reported earlier by Solomon et al., ${ }^{19}$. While the effect of SDS on SDS flooding (solid squares of Fig. 4) show similar trend with incremental surfactant concentration increases the additional oil recovery with a minimum value at $15.0 \%$ and maximum

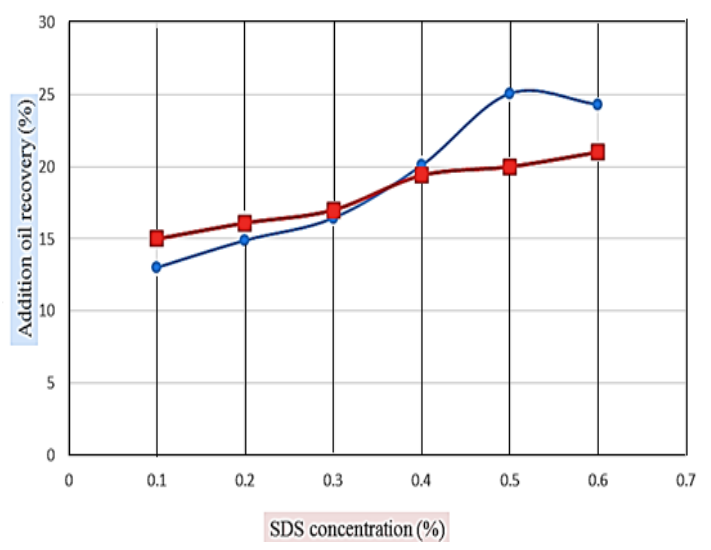

Fig. 4. Additional oil recovery against SDS concentration for •, SDS-Gum Arabic and $\square$, SDS flooding at $21.0 \%$. In the comparison surfactant-polymer flooding the additional oil recovery minimum $13.0 \%$ and maximum $25.0 \%$. Therefore, it can be concluded that the additional oil recovery for SDS-Gum arabic flooding is more effective than only SDS flooding. This is due to the synergic effects of reduction of surface tension by surfactant and improvement of mobility ratio by polymer solution as explained earlier.

\section{CONCLUSION}

In this chemical flooding study, it can be concluded that the concentration of SDS in SDS-Gum arabic slug can affect the quantity of oil recovered. Polymer (Gum Arabic) and SDS are suitable for the mobility control of the enhanced oil recovery process. Using small amount of surfactant reduces the surface tension of liquid (water) appreciably, which increases oil recovery from the oil bank. In addition, the use of gum arabic increases the sweep efficiency by reducing the mobility ratio. The SDS flooding method the oil recovery by approximately 21.0 percent. However, the SDS-Gum arabic system increases the oil recovery by 25.0 percent. This shows that mixtures of SDS-Gum arabic method the recovery oil is increased by 4.0 percent increase compared to SDS flooding.

\section{ACKNOWLEDGEMENT}

This work is supported by Fundamental Research Grant from Ministry of Higher Education, Malaysia (Grant No. 59364) and is gratefully acknowledged.

\section{Conflict of Interest}

The author declares no conflict of interest. 


\section{REFERENCES}

1. Kamal, M.S.; Hussein, I.A.; Sultan, A.S. Review on Surfactant Flooding: Phase Behavior, Retention, IFT, and Field Applications, Energy Fuels., 2017, 31, 7701-7720.

2. Hamza, M.F.; Sinnathambi, C.M.; Aljunid, Z. M. M.; Soleimani, H.; Karl, S.D. An Overview of the Present Stability and Performance of EOR-Foam, Sains Malaysiana., 2017, 46(9), 1641-1650.

3. Negin, C.; Ali, S.; Xie, Q. Application of nanotechnology for enhanced oil recovery- A review, Petroleum., 2016, 2(4), 324-333.

4. Rahman, I.Ab.; Suhaimi, H.; Tiddy, G.J.T. Microemulsions with palm oil derivatives stabilized by a nonionic surfactant: Effects of temperature and cosurfactant, J Disp Sci Technol., 2005, 26(3), 355-364.

5. Aoudia, M.; Al-Shibli, M. N.; Al-Kasimi, L. H.; Al-Maamari, R.; Al-Bemani, A. Novel surfactants for ultralow interfacial tension in a wide range of surfactant concentration and temperature. J. Surfactants Deterg., 2006, 9(3), 287-293.

6. Han, L.;Ye, Z.; Chen, H.; Luo, P.The interfacial tension between cationic gemini surfactant solution and crude oil. J. Surfactants Deterg., 2009, 12(3), 185-190.

7. Abidin, A.Z.; Puspasari, T.; Nugroho, W.A. Polymers For Enhanced Oil Recovery Technology, Procedia Chem., 2012, 4, 1116.

8. Taber, J.; Martin, F.; Seright, R. EOR Screening Criteria Revisited - Part 1: Introduction to Screening Criteria and Enhanced Recovery Field Projects. SPE Reservoir Engineering., 1997, 12(3), 189-198.

9. Feng, X., Guo, X.; Wang, W.; Zhang, N.; Jia, S.; Wang, X. Case Study: Numerical Simulation of Surfactant Flooding in Low Permeability Oil Filed. SPE Enhanced Oil Recovery Conference., 2011.

10. Abhijit, S.; Keka, O.; Ashis. S.; Mandal, A. Surfactant and Surfactant-Polymers Flooding for Enhanced Oil Recovery. Advanced in Petroleum Exploration and Development, $A d v$.
Petrol. Explor. Develop., 2011, 2(1), 13-18.

11. Atsenuwa, J.; Taiwo, O.; Dala, J.; Mohammed, I.; Olafuyi, O. Effect of Viscosity of Heavy Oil (Class-A) on Oil Recovery in SP Flooding Using Lauryl Sulphate and Gum Arabic. SPE Nigeria Annual International Conference and Exhibition., 2014.

12. Avwioroko, J.E.; Taiwo O.A.; Mohammed I.U.; Dala, J.A.; Olafuyi, O.A. A Laboratory Study of ASP Flooding on Mixed Wettability for Heavy Oil Recovery Using Gum Arabic as a Polymer. SPE 172401, SPE-NAICE, Annual Meeting, Lagos., 2014.

13. Orivri, D.U.; Taiwo, O.A., Olafuyi, O.A. Characterizing wettability Effect on Recovery from Surfactant Flooding in a lighty Oil Porous Media. J. Nig. Institution Prod. Engineers., 2014, 17, 143-152.

14. Abidin, A.; Puspasari, T.; Nugroho, W. Polymers for Enhanced Oil Recovery Technology. Procedia Chem., 2012, 4, 11-16.

15. Santanna, V.; Silva, A.; Lopes, H.; Sampaio, N.F. Microemulsion flow in porous medium for enhanced oil recovery. J. Petrol. Sci. Eng., 2013, 105, 116-120.

16. Hongyan, W.; Xulong, C.; Jichao, Z.; Aimei, Z. Development and application of dilute surfactant-polymer flooding system for Shengli oilfield. J. Petrol. Sci. Eng., 2009, 65(1-2), 45-50.

17. Mukerjee, P.; Mysels, K.J. Critical Micelle Concentration of Aqueous Surfactant Systems. US Government Printing Office, Washington DC., 1971, 36, 1-230.

18. Gogoi, S.B. Effluent as surfactant for enhanced oil recovery. Innovative Energy Policies., 2014, 3(1), 1000109.

19. Solomon, U., Oluwaseun, T., \& Olalekan, O. Alkaline-Surfactant-Polymer Flooding for Heavy Oil Recovery from Strongly Water Wet Cores Using Sodium Hydroxide, Lauryl Sulphate, Shell Enordet 0242, Gum Arabic and Xanthan Gum. SPE Nigeria Annual International Conference and Exhibition, 2015; doi:10.2118/178366-MS. 